\title{
FILTROS NA REDE: DAS RELAÇÓES ENTRE DISCURSO E TECNOLOGIA $^{1}$
}

\author{
Dantielli Assumpção Garcia \\ Universidade Estadual do Oeste do Paraná, UNIOESTE, Cascavel, PR, Brasil \\ Laboratório E-L@DIS (PNDP-CAPES)
}

A tese Filtros na rede: das relaçôes entre discurso e tecnologia, de Daiana de Oliveira Faria, orientada pela Profa . Dr. L. D. Lucília Maria Abrahão e Sousa, junto ao Programa de Pós-Graduação em Psicologia da Faculdade de Filosofia, Ciências e Letras de Ribeirão Preto (FFCLRP/USP), apoio FAPESP, traça uma interessante e pertinente discussão - não só para o campo teórico da Análise de Discurso, mas, também, para qualquer área que toma a tecnologia, o ciberespaço e as redes como objetos (TIs, Engenharias, entre outras) - em torno do funcionamento dos recursos de personalização de conteúdos na Internet na pesquisa Google que impóem filtros aos usuários.

Com uma escrita rica e acessível inclusive para um leitor leigo, curioso por saber como funciona o ciberespaço que tanto utiliza, Daiana de Oliveira Faria mostra como os filtros funcionam como formas de controle na rede em que o sujeito que ali navega sente-se um usuário livre, embora, essa liberdade seja controlada. Para a pesquisadora, os filtros "têm o potencial de promover um policiamento dos enunciados na rede, uma espécie de normalização asséptica da leitura e do pensamento" (p. 13).

Refletindo sobre a emergência de uma forma-sujeito histórica da contemporaneidade, a qual nomeia como sujeito-dado, a autora explicita como "a ideologia naturaliza o uso das tecnologias, promovendo um efeito de liberdade dos sujeitos pela facilidade de acesso, pela total disponibilização de qualquer tipo de conteúdo e pelo mito da completude" (p. 14). Questionando as evidências, somos levados pela pesquisadora a navegar em sua escrita, a qual aponta para uma vivência do sujeito na rede, perpassada pela dispersão, pelo controle e pela vigilância imposta pelos filtros de personalização dos conteúdos.

Como ressalta, o sujeito-dado, individuado pelas técnicas, "é fisgado pelo efeito de que está no controle de seus dizeres; de que tem acessibilidade infinita a todo e qualquer tipo de conteúdo; de que é sabedor das técnicas

\footnotetext{
${ }^{1}$ Resumo da tese de doutoramento homônima de Daiana de Oliveira, defendida em 2016, sob orientaçáo da Profa. Dr. L. D. Lucília Maria Abrahão e Sousa, junto ao Programa de Pós-Graduação em Psicologia da Faculdade de Filosofia, Ciências e Letras de Ribeirão Preto, Universidade de São Paulo (PPGP/FFCLRP/USP).
} 
e as domina" (p. 128). Contudo, pelo funcionamento dos filtros de personalização, o sujeito-dado tem poucas brechas de escape na rede: "efeito de evidência naturalizado pelo trabalho da ideologia que faz com que os sujeitos se reconheçam universalmente, no movimento de interpelação, de submissão ao Sujeito" (p. 128).

A escrita de Faria revela, por fim, um interessante percurso teóricoanalítico no qual o funcionamento da rede, dos recursos de personalização de conteúdos, do uso dos filtros é exposto e contradito. Marcando como o espaço da rede, da Internet, não é um lugar em que o sujeito tudo pode fazer e no qual tudo há ali. Há bolhas no ciberespaço que permitem determinados acessos ao sujeito-dado, silenciando outros. 